\title{
Is Autonomy in Language Learning Attainable through Assessment?
}

\author{
Carol J. Everhard \\ Aristotle University of Thessaloniki \\ everhard@enl.auth.gr
}

\section{Abstract}

Peer- and self-assessment seem to be crucial in the promotion of autonomy in EFL higher education; paradoxically, few studies have been conducted in this area. The Assessment for Autonomy Research Project (AARP) examined the assessment-autonomy relationship, through offering $1^{\text {st }}$ year students responsibility for peer- and self-rating of oral and written assignments, using criteria checklists, and awarding real grades. Quantitative and qualitative data were gathered and analysed over a 5-year period, 2005-2010. There was clear evidence that assessment empowerment promoted critical thinking and offered students a greater degree of autonomy than they were hitherto accustomed to.

\section{Introduction}

The relationship between autonomy and assessment could be termed ambivalent, mainly due to the paucity of research in this area, particularly in relation to EFL in higher education. Studies have focused either on speaking or writing, have been of short duration, usually one semester, and have been conducted mainly in the Far East, where modesty prevails among language learners, causing them to rate themselves particularly severely. The Assessment for Autonomy Research Project (AARP), which was conducted over a 5-year period, with $1^{\text {st }}$ Year students on Language Mastery I courses in the School of English (SOE), Aristotle University of Thessaloniki (AUTh), between 2005-2010, provided the opportunity to examine the relationship between assessment and autonomy more closely.

\subsection{Why autonomy?}

Autonomy in language learning has attracted great interest amongst language instructors over the last three decades, yet understanding, concerning what

\section{(cc) BY-NC-ND}


it is and how it can be promoted, is still somewhat vague. The creation of the European Language Portfolio (ELP) and the Common European Framework of Reference (CEFR) have gone some way towards furthering that understanding, since exploitation of the ELP involves learners in evaluation of their learning, through the use of criterial checklists, which promote reflection about learning, and, subsequently, autonomy.

While there have been projects at local, national and international levels designed to encourage use of the ELP and the CEFR, their uptake in Greece seems to have been limited, and their implementation no more than superficial. One explanation might be that the emphasis there during the last three decades has been on "certification" for which students "prepare strenuously" (Sifakis \& Sougari 2010: 305).

According to Little (2003), the public examinations which provide certification have a "powerful washback effect" which can be detrimental to the fostering of autonomy and lead to "teaching for the exam", a view supported in Greece by Prodromou (1995) and Vassilakis (Spyropoulou 2006). Testing and examinations breed fear (Boukouvalas 2001), make unreasonable demands on young people (Broadfoot 2005), and also breed reliance on more knowledgeable others (Everhard 2006), leading learners towards greater heteronomy.

\subsection{Heteronomy vs. Autonomy}

Speakers and writers on autonomy in language learning tend to define from the outset what they mean by autonomy, to ensure that the listener or reader has the same conception of autonomy in their minds. However, only rarely do experts mention that the word autonomy has an opposite, of similar derivation, which is 'heteronomy' (Namenwirth 1996; Rujiketgumjorn 2000; Schmenk 2006), as shown in Table 1 below:

Table 1.

Derivation and meaning of autonomy and heteronomy

\begin{tabular}{|c|c|c|}
\hline WORD & GREEK DERIVATION & MEANING \\
\hline autonomy & $\begin{array}{l}\alpha v \tau o ́ \varsigma=\text { self } \\
\text { vómos }=\text { law }\end{array}$ & $\begin{array}{l}\text { rule, } \\
\text { regulation, } \\
\text { direction of self }\end{array}$ \\
\hline heteronomy & 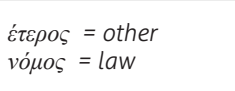 & $\begin{array}{l}\text { rule, } \\
\text { regulation, } \\
\text { direction by others }\end{array}$ \\
\hline
\end{tabular}

In foreign language learning, it can be useful not only to remember the antithesis between these two words, but also to think in terms of a continuum from heteronomy to autonomy, though not a continuum with fixed gradations or 
stages, but rather one which allows for greater or lesser degrees of autonomy and heteronomy and permits of progression, regression and a great deal of fluctuation in both directions (see Figure 1 below). Thus, language instructors remain aware that certain behaviours (Breen \& Mann 1997: 145), promoted in the language-learning arena, are more or less conducive to autonomy and/or heteronomy.

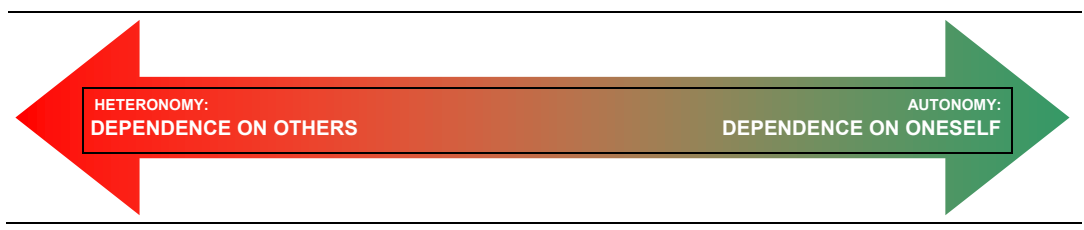

Figure 1. Heteronomy and autonomy on a continuum

Schmenk (2006) insists we should not regard the polarity between heteronomy and autonomy as one of bad vs. good. Nevertheless, non-linguists remind us that dependence on others, while not always a bad thing, can be "debilitating" (Boud 1996: 44) and can constitute a "severe limitation" (Grow 1991: 129). Dependence on others, if perpetuated, may result in the phenomenon of "learned helplessness" (Dornyei 1994: 276), where learners are overcome by a feeling of powerlessness, remaining entrapped in the belief that things cannot be otherwise.

Some researchers suggest we regard autonomy as a right (Hustler \& Hodkinson 1996; Rujiketgumjorn 2000), or an entitlement (Wright 2005). Although this may sound extreme, it is important to consider the consequences, for our learners, of the continued promotion of heteronomy (Everhard 2006); thus, it is important to consider the more positive role assessment can play in the empowerment of learning.

\subsection{Why Assessment?}

Lewkowicz \& Moon (1985: 62) describe assessment as a "powerful weapon of control", while Gibbs (1999: 41) regards it as "the most powerful lever teachers have" to influence students' attitudes towards learning. By placing emphasis on grades and achievement in tests, education systems promote surface rather than deep learning and, in language learning, focus on what is likely to appear in the exam (Prodromou 1995; Spyropoulou 2006), ignoring other knowledge useful to a language learner and user.

If such learning prevails through to higher education, according to McKay $\theta$ Kember (1997: 55), students will "wish to be spoon fed and in turn they are 
spoon fed", with responsibility for learning remaining with the teacher. This conflicts with what Kohonen (1992: 18-19) sees as the "task" of education, which should enable learners to become "a 'fuller' person with the capacity to reason, to feel and to act responsibly", which can only be achieved through "an increasing capacity to assume responsibility for what one does".

\subsection{Degrees of Autonomy and Assessment}

The aim of the AARP was to examine Harris \& Bell's (1990: 111) suggestion, that the greater degree of involvement learners have in assessment procedures, the greater the degree of autonomy they enjoy, and to see if by combining it with Dam (1995) and Little's (1996; 1999) 4 levels of necessary understanding for autonomy (see Figure 2 below), it was possible for participants to "assume responsibility" and become "fuller" persons (Kohonen ibid).

Through the use of common criterial checklists, like those in Appendices 1, 2 \& 3, it was possible to move from purely teacher-controlled to more learnercontrolled assessment, with Peer-assessment preceding, and being used as a springboard to Self-assessment (see Figure 2 below).

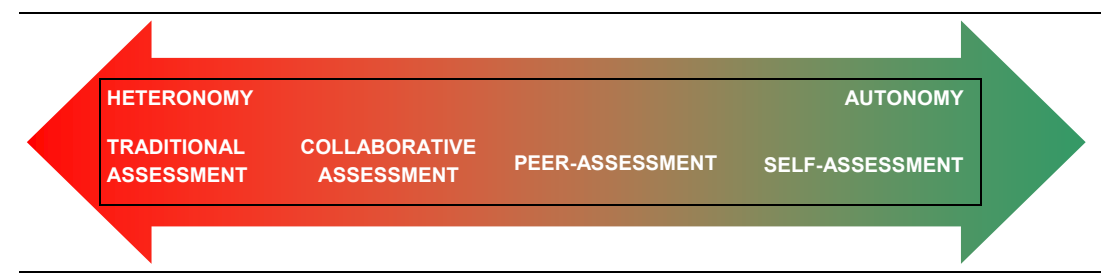

1. WHAT are we learning?

2. WHY are we learning?

3. How are we learning?

4. With WHAT SUCCESS?

Figure 2. Combining degrees of assessment and levels of necessary understanding

\subsection{Turning a Constraint into an Affordance}

To turn assessment into an affordance, rather than a constraint in achieving autonomy, learners have to exercise critical thinking, or what Heron (1981: 66) refers to as "criterial thinking". Such thinking deepens learners' understanding of the subject-matter since "measuring" or "judging" work against criteria involves 
"far more rigorous processes than simply reading, listening or watching" (Race 1998: 114). In the AARP, by "learning to assess" and by "assessing to learn" (Chen 2008: 254), learners would, hopefully, prove themselves competent and trustworthy assessors.

\section{Research Methodology}

To obtain information about both the products and the processes of assessment on the AARP, a mixed-methods approach was deemed suitable for gathering both quantitative and qualitative data.

\subsection{Context}

The research groups were those assigned to the Instructor-Researcher (I-R) on the obligatory course Language Mastery I (LM I), in the SOE, AUTh, which were therefore convenience samples. LM I is taken in the autumn semester, ranging between 10-13 weeks in length, and focuses on descriptive and narrative discourse.

The AARP was conducted in three stages:

(1) the Pre-Study, 2005-2006;

(2) the Main Study, 2006-2009, and

(3) the Post-Study, 2009-2010.

There were two cycles of writing assessment, based on two home writing assignments and one cycle of speaking assessment, based on in-class presentations. Groups ranged between 18 to 30 in number, and involved 246 students in total. A reliable international placement test determined the participants' level of English, with CEFR B2 level predominating, and details of previous certification were also gathered.

The majority of SOE graduates become teachers of EFL in state or private $\mathrm{FL}$ schools, so assessment skills are relevant to their future lives and careers.

\subsection{Hypotheses and Aims}

The four working hypotheses on which the AARP was based were, if learners could:

(1) peer-assess oral and writing skills, using predetermined criteria, with objectivity and reliability;

(2) self-assess oral and writing skills, using predetermined criteria, with objectivity and reliability; 
(3) assume ownership of the assessment criteria checklists and assess in an atmosphere of cooperation and trust; and whether triangulated assessment could

(4) become an affordance, leading to greater self-direction and autonomy.

These working hypotheses would be tested in the Pre-Study, through particular pedagogical procedures and, if proved satisfactory, would be applied in the years that followed.

\subsection{Research Instruments}

Instruments used in the collecting of data were (a) criteria checklists for two writing assignments and one oral assignment (see sample Appendices 1, 2 \& 3 ), and (b) assessment questionnaires (see Appendix 4). Additional information was also gathered on Student Profile Cards and Learner/Teacher Contracts, but these were used to track progress by the I-R and AARP participants only (Everhard 2012).

Since learners were novices in assessment and responsibility for rating and grading was shared equally between Self, Peer and the I- $R$, in each instance, they used criteria which were:

(a) pre-determined by the I-R, without negotiation ${ }^{1}$;

(b) a simple check-list with five criteria on a Likert scale from 1-5;

(c) known to participants in the pre-production stage of the assignment,

(d) familiar to them through peer-assessment processes.

The criteria selected were holistic, avoiding specific categories such as 'grammar' and 'vocabulary' included by many other researchers. Research groups were mixed ability, so some students might be aware of their own competence or inadequacy in these areas and be negatively influenced.

Figure 3 below distinguishes the differences between peer-assessment of writing and speaking. Only one Peer assessed each writing assignment, with their rating holding equal status with that of the Instructor or Self-assessor, while, with speaking, each member of the audience peer-assessed the presenter.

1 Formerly, researchers insisted that students should negotiate or create their own criteria, but recently Orsmond et al. (2000) found that this did not guarantee ownership of the criteria. 


\section{WRITING SKILLS}

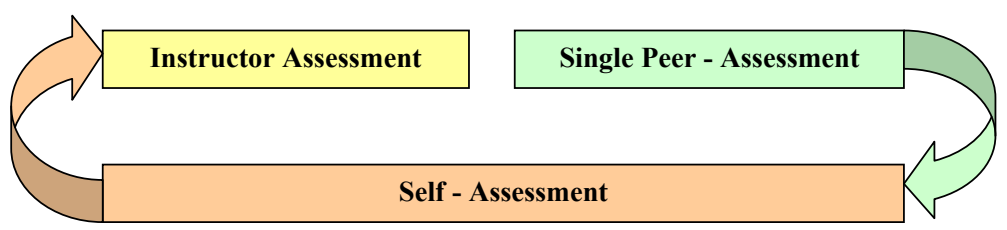

ORAL SKILLS

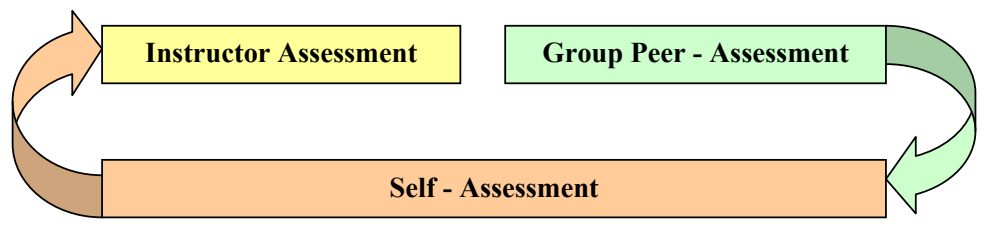

Figure 3. Assessment Cycle for Writing and Oral Skills

\subsection{Data Gathering}

The AARP was a replicative study, year on year, fitted into normal teaching procedures to avoid unnecessary disruptions. Thus, the criteria checklists (see Appendices 1, 2 \& 3), used in triangulated Peer-, Self- and Instructor assessment, served a dual purpose in a) configuring students' assignment grades, and b) comparing Peer-, Self- and Instructor ratings statistically. Each of the five criteria were assessed on a Likert scale of 1 to 5 , with 1 = weak, 2 = moderately weak, $3=$ average, $4=$ moderately strong and $5=$ strong. The total grade, of 25 , was downscaled to 10 .

At the end of the assessment process, a questionnaire (see Appendix 4) was used to formulate participants' impressions and create a fuller picture of assessment success. The questionnaire used, 2005-2009, was an abridged version of one created by Antonopoulou (Antonopoulou et al. 2008) in 2002. Responses to the 10 questions were on a Likert scale of 1 to 5 , where 1 = completely disagree, $2=$ tend to disagree, 3 = undecided, $4=$ tend to agree, and $5=$ completely agree. $\mathrm{A}$ new questionnaire (Everhard-Theophilidou 2012) was devised in the year 2009 to gather information about assessment intervention in the Post-Study.

\subsection{Assessment Recording and Research Procedures}

In the case of writing assessment, all the participants used single criteria checklists and, for both peer- and self-assessment were encouraged to make corrections 
and comments on the texts, just as the instructor would do. Consequently, not just the grading would be triangulated, but also feedback. The assignment grade awarded to individuals was based on the average of Self-, Peer- and Instructor grades. In the case of peer-assessment of speaking, the instructor collected all the checklists, averaged the grade, added the grades from Self and Instructor, and calculated the average overall. Grades were recorded on Student Profile Cards, and electronically, for further analysis.

\subsection{Statistical Analysis}

All of the data gathered concerning Self-assessment (S-A), Peer-assessment (PA) and Instructor-assessment (I-A), from each assignment completed on LM I, in each year of the AARP, in the Pre-, Main and Post-Study, was subjected to the same methods of statistical analysis. The Means, in each case, from each type of assessment, whether S-A, P-A or I-A, for each group, for each assignment, were subjected to One-Way Analysis of Variance (ANOVA), where $p=.05$, to permit comparison. Where significant differences were found, further analysis using the Tukey-Kramer Comparison Test of Pairwise Mean Differences was deployed.

Assessment data was also analysed using the Pearson product-moment correlation coefficient $(r)$, where $r=.05$, to determine possible relationships between S-A and P-A (S-P), S-A and I-A (S-I), P-A and I-A (P-I).

Chi-Square Tests were conducted (Everhard-Theophilidou 2012) with the pooled data from the two research groups each year, to determine any Self:Instructor (S:I), Peer:Instructor (P:I) and Self:Peer (S:P) rating frequency ratio patterns.

Regarding the questionnaires, these were distributed at the end of each autumn semester. Frequency counts were conducted on the responses to each question by each participant and the data was recorded electronically. It was processed in two different ways:

(1) using percentages which were displayed in xyz graphs, facilitating comparison;

(2) according to the means of responses, which were subjected to t-analysis, permitting comparison between each pair of groups, from 2005 to 2009.

The same procedures were followed with Post-Study questionnaires, this time for 22 questions (Everhard-Theophilidou 2012).

Comments from students shed light on the 'processes' in students' minds and their attitudes to the assessment experience. Answers to three open questions (see Appendix 4) in the Pre- and Main Studies, were recorded for further analysis. In the case of the Post-Study, space provided after each of the 22 questions furnished useful comments on intervention processes. 


\section{Results}

The statistical analyses outlined above, produced very interesting results, an overview of which can be found in Table 2 below. Brief summaries of the results are given in the sections which follow.

\subsection{Assessment of the $1^{\text {st }}$ Home Writing Assignment}

ANOVA analysis of the $1^{\text {st }}$ Home Writing Assignment (Writing 1 ) assessment, produced no significant differences in either Group A or Group B, indicating overall alignment between S-A, P-A and I-A in the AARP Pre-Study. However, in the three consecutive years of the Main Study (2006-2009), the first and larger of the two groups in each year produced significant differences, and this same pattern is repeated in the Post-Study (2009-2010). Groups A, B, D, F, H and J appear to demonstrate competence in their assessment, giving an overall success rate of around $60 \%$ among the total student constellation over the fiveyear period.

If we also take into account the Pearson Product Moment correlation coefficients, the picture looks even more favourable, particularly in the case of Group C, 2006-2007, where we have correlation coefficients both in the case of Self-Instructor (S-I), of 0.61 and Peer-Instructor (P-I), of 0.62 , which are very encouraging. The S-I correlation of 0.51 for Group F also offers confirmation that things went well, while the P-I correlation of 0.66 for Group ] in the Post-Study, with Intervention, is also heartening.

Although not displayed here, it should be mentioned that frequency rating ratios derived from chi-square test analyses showed, firstly, that in the PreStudy, S:I frequency rating ratios and P:I ratios, were very similar. Secondly, these same ratios continued to follow a very similar pattern of rises and falls throughout the AARP, although, for the most part, the S:I frequency rating ratios are more deviant. Thirdly, in the Post-Study, 2009-2010, the Intervention Exercise appeared to have a less positive effect on P-A and S-A rating than hoped for.

\subsection{Assessment of the $2^{\text {nd }}$ Home Writing Assignment}

An appraisal of assessment processes based on comparison of the means of true scores from S-A, P-A and I-A of the $2^{\text {nd }}$ Home Writing Assignment, initially appears more disappointing than the $1^{\text {st }}$ Home Writing Assignment. The same behavioural pattern occurs in the Pre-Study, with no significant differences in Groups $A$ and $B$, demonstrating assessment alignment. The same behavioural 
Major Trends in Theoretical and Applied Linguistics

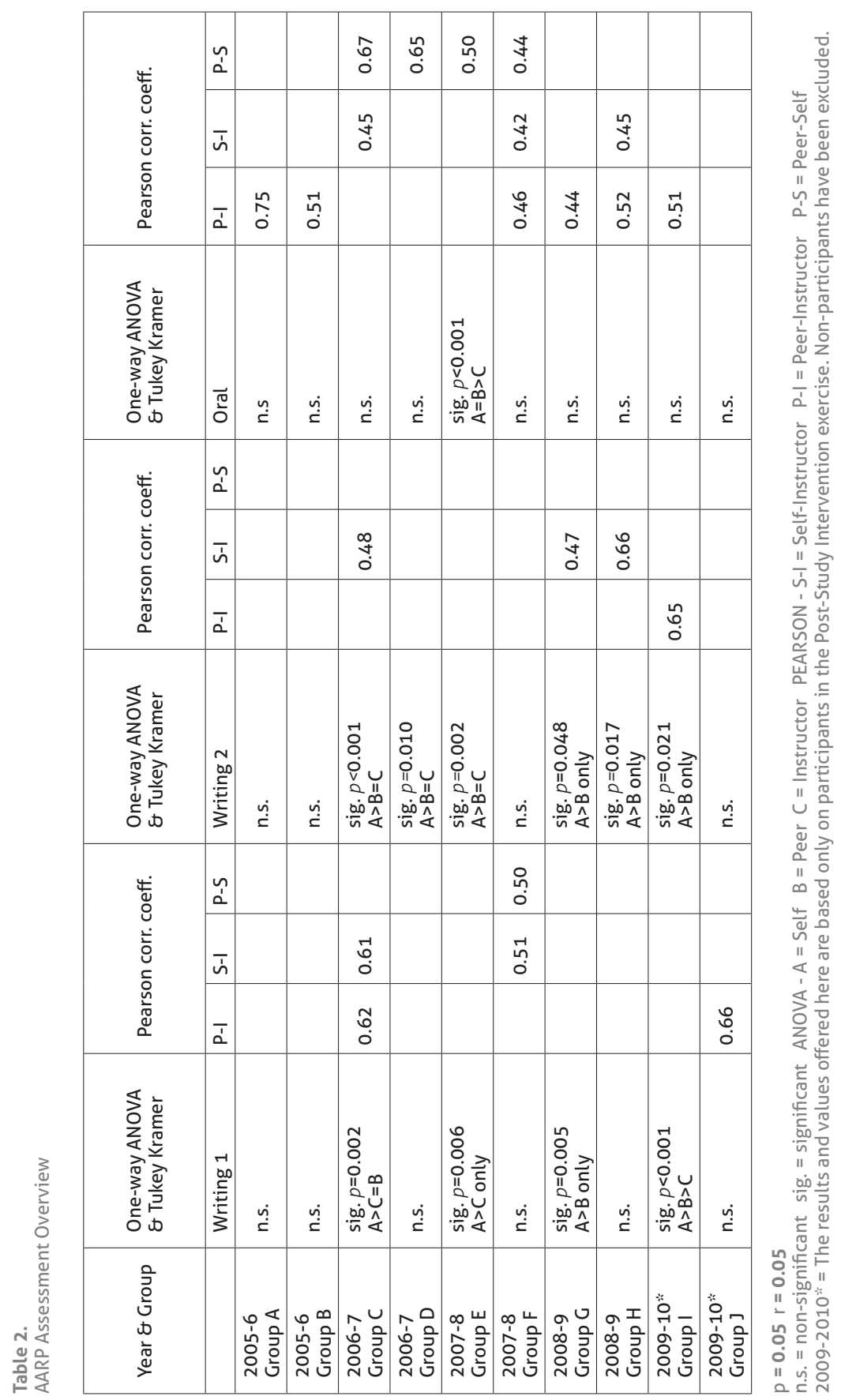


patterns also occur in the Post-Study, with significant differences in Group I and no significant differences in Group J. From thereon the similarity in assessment patterns ends and instead we have significant differences in five out of the six groups in the Main Study, with the same pattern of $A>B=C$ occurring in three of those, namely Groups C, D and E, indicating over-inflated self-assessment but alignment between $\mathrm{P}$-I.

Our picture of the $2^{\text {nd }}$ Writing Assignment changes when we take correlation coefficients into consideration. S-I correlations occur in three of the groups from the Main Study, namely Groups C, G and H, which is a very encouraging sign. In the Post-Study, Group ] has a correlation coefficient occurring between P-I, which is also satisfying. This seems to bring the level of assessment success to the same level as the $1^{\text {st }}$ Writing Assignment, which is approximately $75 \%$ over the five-year period.

Regarding rating frequency ratios (not shown here) derived from chi-square test analysis (Everhard-Theophilidou 2012), the ratios in all categories in the Pre-Study, 2005-2006, show the greatest restraint and closeness. Restraint also occurs in the Post-Study, both in the I:S value which has been reduced from 1:5 to $1: 1.7$ and also in the I:P value, reversed since the $1^{\text {st }}$ Writing assessment cycle, from $1: 3.1$ to $1.5: 1$. There seems to be a delayed reaction to Intervention in the $1^{\text {st }}$ assessment cycle, with feedback fed forward into the $2^{\text {nd }}$ assessment cycle, a phenomenon described elsewhere, but in relation to Oral assessment (Cheng \& Warren 1999).

\subsection{Assessment of Oral Assignments}

Initial impressions of oral assessment results, based on analysis of the means of true scores from S-A, P-A and I-A, for the Pre-Study (2005-2006), are the same as with writing, with no significant differences in either group, and no significant differences in five out of the six groups in the Main Study, with the one exception being Group E, 2007-2008, which also performed poorly on assessment of both the writing assignments.

Pearson correlation coefficients offer confirmation of assessment success through P-I correlations for 5 and S-I correlations for 3 of the 10 groups. Group F, 2007-2008, has similar correlations for P-I, S-I and P-S, and emerges as the most successful group of all, while P-I and S-I correlations for Group H, 2008-2009, confirm healthy assessment alignment.

Rating frequency ratios derived from chi-square test analysis (EverhardTheophilidou 2012), not displayed here, showed the greatest equilibrium between ratios in the Main Study, 2008-2009. An identical I:P value and the same equilibrium appears in the Post-Study. I:S ratios in the Pre-study are close to equalisation, with $1: 1.2$, which rises sharply in the following year, 
2006-2007, and continues to rise steeply, in 2007-2008, only to drop sharply in 2008-2009, and rise slightly in the Post-Study.

Peaks for all ratios in 2007-2008 offer convincing evidence, of the vagaries of Group E, while close agreement between all ratios in 2008-2009, shows co-incidence that might have been expected the following year, due to Intervention. The I:S ratio in the Pre-Study, with the exception of 2008-2009, never came close to repetition, but instead was usurped by the I:P ratio in 2006-2007, 2008-2009 and 2009-2010, and is close to equalisation in all cases.

\section{Discussion}

In the Pre-Study, there is evidence of strong assessment alignment with regard to both writing and speaking and the correlation coefficients produced between $\mathrm{P}-\mathrm{I}$ in oral assessment are particularly gratifying. Questionnaire analysis also revealed that students in the Pre-Study felt they had greatly benefitted from the assessment process.

In the Main Study, while the evidence of assessment alignment is not so immediately transparent with regard to writing, with only Group F producing ANOVA results consistent with those of Groups $A$ and $B$, attention to the TukeyKramer results for Groups C, D, E, G and $\mathrm{H}$ in the $2^{\text {nd }}$ Writing Assignment give evidence of Peer-Instructor consistency, while the correlation coefficients for $1^{\text {st }}$ and 2 nd writing assignments produced by Groups C, F, G and $\mathrm{H}$ give evidence of Self-Instructor consistency. In the case of speaking, the assessment alignment achieved in the Pre-Study was maintained in the Main Study, with the exception of one group, Group E, which constituted a rogue group. Closer inspection of participants in Group E revealed greater collaboration in pairs or groups in the presentation of their oral assignments, while all participants in Group F presented alone. This collaboration for Group E may have extended to assessment processes, resulting in friendship marking.

The mixed results of the Main Study led the I-R to implement Intervention in the Post-Study in 2009-2010. While previously peer-assessment had been used as training for self-assessment, students were now offered training, through various intervention exercises (IE)s, before undertaking the peer-assessment process. Interestingly, assessment alignment in the Post-Study, both in the speaking IE and the writing IE, was impressively consistent; however, when it came to real assessment procedures, the IEs seemed to have little, no, or a delayed effect, making them seemingly redundant. This apparent redundancy was confirmed by qualitative data. This led to the conclusion that peer-assessment processes in themselves, as conducted in the Pre- and Main Studies, were sufficient practice for undertaking self-assessment, both in speaking and writing. 


\section{Conclusion}

The AARP was a long-term study which was unique both in its simplicity and in its investigation of both writing and speaking assessment, with the same groups of students. Like some previous studies, there was evidence that peers could assess writing and speaking skills accurately, using criteria checklists, and that this was performed in an atmosphere of cooperation and trust. In addition, there were indications, albeit less, that students could self-assess speaking and writing skills, without exploiting their position of power. In contrast with previous studies of self-assessment, modesty did not seem to be an issue.

Clearly, previous societal, cultural and academic conditioning all play their role in learners' willingness to assume responsibility for assessment and to move further along the path to autonomy. It is also evident that the relationship between assessment and autonomy in EFL deserves much greater attention. 


\section{References}

Antonopoulou, N., C. Everhard and E. Joycey. 2008. Use of peer-assessment and self-assessment with students in tertiary-level education. Journal of Applied Linguistics 24: 53-78.

Boud, D. 1996. Some competing traditions in experiential learning. In S.W. Weil and I. McGill (eds.), Making sense of experiential learning: Diversity in theory and practice. Buckingham: SRHE and Open University Press, 38-49.

Boukouvalas, J. June, 2001. Exams - the necessary evil. PALSO, Athens: Enimerosi, p.9.

Breen, M.P. and S.J. Mann. 1997. Shooting arrows at the sun. In P. Benson and P. Voller (eds.), Autonomy and independence in language learning. London and New York: Addison Wesley Longman, 132-149.

Broadfoot, P. 2005. Dark alleys and blind bends: Testing the language of learning. Language Testing 22(2): 123-141.

Chen, Y.-M. 2008. Learning to self-assess oral performance in English: A longitudinal case study. Language Teaching Research 12(2): 235-262.

Cheng, W. and M. Warren. 1999. Peer and teacher assessment of the oral and written tasks of a group project. Assessment and Evaluation in Higher Education 24(3): 301-314.

Dam, L. 1995. Learner Autonomy, 3: From Theory to Practice. Dublin: Authentik.

Dornyei, Z. 1994. Motivation and motivating in the foreign language. The Modern Language Journal, 78(3): 273-284. 
Everhard, C. 2006. Returning the dancing bears to the wild! $40^{\text {th }}$ International Annual IATEFL Conference, 8-12 April, 2006, Harrogate, U.K.

Everhard-Theophilidou, C. J. 2012. Degrees of autonomy in foreign language learning. PhD Dissertation, Department of Theoretical and Applied Linguistics, School of English, Aristotle University of Thessaloniki.

Gibbs, G. 1999. Using assessment strategically to change the way students learn. In S. Brown and A. Glasner (eds.), Assessment matters in higher education: Choosing and using diverse approaches. Buckingham and Philadelphia, PA: Open University Press, 41-53.

Grow, G.O. 1991. Teaching learners to be self-directed. Adult Education Quarterly 41(3): 125-149.

Harris, D. and C. Bell. 1990. Evaluating and assessing for learning (2nd ed.). London and New York: Kogan Page and Nichols Publishing.

Heron, J. 1981. Assessment revisited. In D. Boud (ed.), Developing student autonomy in learning. London: Kogan Page, 55-68.

Hustler, D. and P. Hodkinson. 1996. Rationales for student-centred learning. In R. Halsall and M. Cockett (eds.), Education and training 14-19: Chaos or coherence?. London: David Fulton Publishers, 108-119.

Kohonen, V. 1992. Experiential language learning: Second language learning as cooperative learner education. In D. Nunan (ed.), Collaborative language learning and teaching. Cambridge: Cambridge University Press, 14-39.

Lewkowicz, J.A. and J. Moon. 1985. Evaluation: A way of involving the learner. In J.C. Alderson (ed.), Evaluation. Oxford: Pergamon Press, 45-80.

Little, D. 1996. Learner autonomy in theory and practice: APAC ELT Convention, 29 Feb. - 2 March, Barcelona.

Little, D. 1999. Autonomy in second language learning: Some theoretical perspectives and their practical implications. In C. Edelhoff and R. Weskamp (eds.), Autonomes Fremdsprachenlernen. Munich: Max Hueber Verlag, 22-36.

Little, D. 2003. Learner autonomy and public examinations. In D. Little, J. Ridley and E. Ushioda (eds.), Learner autonomy in the foreign language classroom: Teacher, learner, curriculum and assessment. Dublin: Authentik, 223-233. 
McKay, J. and D. Kember. 1997. Spoon feeding leads to regurgitation: A better diet can result in more digestible learning outcomes. Higher Education Research and Development 16(1): 55-67.

Namenwirth, E. 1996. Lever l'ambiguïté au sujet du terme d'autonomie? In G. Aub-Buscher (ed.), The linguistic challenge of the new Europe. Plymouth: CercleS, 23-35.

Orsmond, P., S. Merry and K. Reiling. 2000. The use of student derived marking criteria in peer and self-assessment. Assessment and Evaluation in Higher Education 25(1): 23-38.

Prodromou, L. 1995. The backwash effect: From testing to teaching. English Language Teaching Journal, 49(1): 13-25.

Race, P. 1998. Practical pointers on peer-assessment. In S. Brown (ed.), Peer assessment in practice: SEDA paper 102. Birmingham: SEDA, 113-122.

Rujiketgumjorn, S. 2000. The control and dependency continuum in self-access. Independence, Newsletter of the IATEFL Learner Autonomy Special Interest Group, 28, 2-3.

Schmenk, B. 2006. CALL, self-access and learner autonomy: A linear process from heteronomy to autonomy? In T. Harden, A. Witte and D. Köhler (eds.), The concept of progression in the teaching and learning of foreign languages. Oxford: Peter Lang, 75-90.

Sifakis, N.C. and A.-M. Sougari. 2010. Between a rock and a hard place. In C. Gagliardi and A. Maley (eds.), EIL, ELF, Global English: Teaching and learning issues. Bern: Peter Lang, 301-320.

Spyropoulou, A. January, 2006. It's a sad fact that we teach for the exams. ELT News, Athens. Retrieved September 29, 2010 from http://www.eltnews.gr/ printinterview. asp? interview_id=30

Wright, V. 2005. Independent learning. In J. Coleman (ed.), Effective learning and teaching in modern languages. London: Routledge, 133-141. 


\section{Appendix 1}

\section{Paragraph writing: assessment criteria checklist}

Writer's St. No.:

Assessor's St. No.:

Use the following criteria checklist:

1 =weak 2 =Moderately weak 3 =Average $4=$ Moderately strong $5=$ Strong

The language was precise and contained few errors

$\begin{array}{llllll}1 & 2 & 3 & 4 & 5\end{array}$

The paragraph had relevant and related content

$\begin{array}{lllll}1 & 2 & 3 & 4 & 5\end{array}$

The paragraph was of right size and well constructed around its topic
2
3
4
5

1

The paragraph flow was logical and helped the reader

$\begin{array}{llllll}1 & 2 & 3 & 4 & 5\end{array}$

The paragraph maintained interest throughout

1

2

3

4

To calculate the grade:-

Add the five ratings together.

Multiply the total by four.

Divide by ten.

Grade awarded to PEER / SELF: 


\section{Appendix 2}

\section{Narrative/descriptive essay writing: assessment criteria checklist}

Code number of writer:

Code number of assessor:

Use the following criteria checklist:

$1=$ Weak $2=$ Moderately weak $3=$ Average $4=$ Moderately strong $5=$ Strong

The essay conveyed an interesting message from beginning to end

$\begin{array}{lllll}1 & 2 & 3 & 4 & 5\end{array}$

All the information in the description was relevant and clear

$\begin{array}{lllll}1 & 2 & 3 & 4 & 5\end{array}$

Ideas were imaginative and nicely linked

$\begin{array}{lllll}1 & 2 & 3 & 4 & 5\end{array}$

Language was correct and used to good effect

$\begin{array}{llllll}1 & 2 & 3 & 4 & 5\end{array}$

The text was well-constructed and well-organised

$\begin{array}{llllll}1 & 2 & 3 & 4 & 5\end{array}$

To calculate the grade:-

1. Add the five ratings together.

2. Multiply the total by four.

3. Divide by ten.

Grade awarded to PEER / SELF: 


\section{Appendix 3}

\section{Oral presentation: assessment criteria checklist}

Presenter's Name/No:

Assessor's St. No.:

Topic presented:

Date:

Use the following criteria checklist:

1 =weak 2 =Moderately weak 3 =Average $4=$ Moderately strong $5=$ =Strong

The presentation appears to be well-prepared

$\begin{array}{lllll}1 & 2 & 3 & 4 & 5\end{array}$

The content and materials are appropriate and interestingly presented

1

23

34

5

The order of the presentation is cohesive and flows without too much reliance on notes

$\begin{array}{lllll}1 & 2 & 3 & 4 & 5\end{array}$

The parts of the presentation are well-linked together

$\begin{array}{lllll}1 & 2 & 3 & 4 & 5\end{array}$

Ability to be understood (voice, delivery, pronunciation etc.)

1

2

3

4

5

To calculate the final grade:-

1. Add the five ratings together.

2. Multiply the total by four.

3. Divide by ten.

Grade awarded to PEER / SELF: 


\section{Appendix 4}

\section{AARP research assessment questionnaire}

Circle the numbers that represent how you feel about aspects of the assessment. $1=$ Completely disagree $2=$ Tend to disagree $3=$ Undecided $4=$ Tend to agree $5=$ Completely agree

It was an interesting form of assessment.

$\begin{array}{lllll}1 & 2 & 3 & 4 & 5\end{array}$

I understood why this method of assessment was being used.

$\begin{array}{lllll}1 & 2 & 3 & 4 & 5\end{array}$

It was easy to assess the work of my peers (peer-assessment).

$\begin{array}{lllll}1 & 2 & 3 & 4 & 5\end{array}$

It was easy to assess my peers objectively.

$\begin{array}{lllll}1 & 2 & 3 & 4 & 5\end{array}$

It was easy to assess my own work (self-assessment).

$\begin{array}{lllll}1 & 2 & 3 & 4 & 5\end{array}$

It was easy to assess myself objectively.

$\begin{array}{lllll}1 & 2 & 3 & 4 & 5\end{array}$

The criteria checklists helped me to:

understand the areas in which I was being assessed.

$\begin{array}{lllll}1 & 2 & 3 & 4 & 5\end{array}$

be a more active participant in the lessons.

$\begin{array}{lllll}1 & 2 & 3 & 4 & 5\end{array}$

pay attention to points I might otherwise have ignored.

$\begin{array}{llllll}1 & 2 & 3 & 4 & 5\end{array}$

develop critical thinking skills.

$\begin{array}{lllll}1 & 2 & 3 & 4 & 5\end{array}$

1. What were the strong points of the method?

2. What were the problems you encountered?

3. What suggestions would you make to improve the method? 